\title{
Photometric Calibration of the SPREAD at the FTU Tokamak
}

\author{
M. J. May
}

\section{December 1, 1999}

Lawrence

Livermore

National

Laboratory

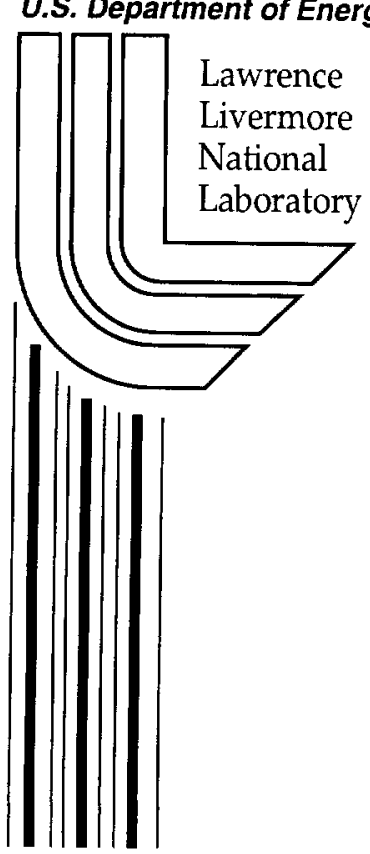




\section{DISCLAIMER}

This document was prepared as an account of work sponsored by an agency of the United States Government. Neither the United States Government nor the University of California nor any of their employees, makes any warranty, express or implied, or assumes any legal liability or responsibility for the accuracy, completeness, or usefulness of any information, apparatus, product, or process disclosed, or represents that its use would not infringe privately owned rights. Reference herein to any specific commercial product, process, or service by trade name, trademark, manufacturer, or otherwise, does not necessarily constitute or imply its endorsement, recommendation, or favoring by the United States Government or the University of California. The views and opinions of authors expressed herein do not necessarily state or reflect those of the United States Government or the University of California, and shall not be used for advertising or product endorsement purposes.

This work was performed under the auspices of the U.S. Department of Energy by the University of California, Lawrence Livermore National Laboratory under Contract No. W-7405-Eng-48.

This report has been reproduced directly from the best available copy.

Available electronically at http://www.doc.gov/bridge

Available for a processing fee to U.S. Department of Energy

And its contractors in paper from

U.S. Department of Energy

Office of Scientific and Technical Information

P.O. Box 62

Oak Ridge, TN 37831-0062

Telephone: (865) 576-8401

Facsimile: (865) 576-5728

E-mail: reports@adonis.osti.gov

Available for the sale to the public from

U.S. Department of Commerce

National Technical Information Service

5285 Port Royal Road

Springfield, VA 22161

Telephone: (800) 553-6847

Facsimile: (703) 605-6900

E-mail: orders@ntis.fedworld.gov

Online ordering: http://www.ntis.gov/ordering.htm

OR

Lawrence Livermore National Laboratory

Technical Information Department's Digital Library

http://www.llnl.gov/tid/Library.html 


\title{
Photometric Calibration of the SPRED at the FTU Tokamak
}

\author{
by
}

Dr. Mark J. May

December 1999 


\section{Photometric Calibration of the SPRED Spectrometer at FTU Tokamak, Frascati Italy}

The SPRED spectrometer was photometrically calibrated by using the FTU tokamak plasma and the Grazing Incidence Time Resolving Spectrometer (GRITS) from the Johns Hopkins University [Stratton, Nucl. Fusion, Vol. 24, No. 6, pp. 767-777, 1984 ]. The photometric calibration of the GRITS spectrometer was transferred to the SPRED [ Fonck, R.J., Applied Optics, Vol. 21, No. 12, p. 2115 (1982) ] by directly comparing the intensity of bright lines emitted from the FTU tokamak plasma that were simultaneously measured by both spectrometers. The GRITS spectrometer ( $\lambda=10-360 \AA ; \Delta \lambda \sim 0.7 \AA)$ was photometrically calibrated in the 50 - $360 \AA$ spectral range at the SURF II synchrotron light source at NIST in Gaithersburg MD in August 1997. The calibration of each SPRED grating was performed separately. These gratings covered the short wavelengths: $100-300$ $\AA(\Delta \lambda \sim 1.4 \AA)$ and the long wavelengths: $200-1800 \AA$ ( $\Delta \lambda \sim 7 \AA)$. This calibration should be accurate until the microchannel plate of the SPRED is exposed to atmospheric pressure. This calibration is similar to the one obtained by Stratton [Stratton, Rev. Sci. Instrum. 57 (8), pp. 204,3 August 1986].

\section{I) The Short Wavelength Grating (100 - $300 \AA)$}

The calibration of this grating was straightforward. The direct comparison of the intensities of bright lines measured by both spectrometers between 100 - $300 \AA$ during the same plasmas were used to transfer the calibration. These lines consisted of intrinsic impurities and those of krypton gas that was puffed into the plasma during the November to December 1997 run period. For these measurements the SPRED's reticon integration time was $20 \mathrm{~ms}$ and microchannel plate high voltage was $800 \mathrm{~V}$. This ASSUMES that the calibration in Show is normalized to $750 \mathrm{~V}$. To adjust the calibration to $800 \mathrm{~V}$ divide by 2.5 . The GRITS reticon integration time was $11.5 \mathrm{~ms}$. The ratio of the intensities of each line measured by the GRITS and the SPRED are plotted in figure \#1. The best fit to this data is the photometric calibration of the SPRED. The error in the GRITS photometric calibration was $\pm 20 \%$. The error in the SPRED calibration was calculated to be $\pm 35 \%$

The best fit to the data is:

$$
\Gamma=2.1995 \times 10^{9} \exp (-0.0021901 * x): R=0.48
$$




\section{II) The Long Wavelength (200 - $1800 \AA$ )}

The photometric calibration of the SPRED's long wavelength grating was more difficult and had a higher inherent error. The calibration was performed in two steps. First, a series of bright lines emitted from intrinsic impurities and Ar puffed into the plasma were measured by both instruments in the region of spectral overlap (200 and $360 \AA$ ). The calibration in this region was obtained in a similar method as detailed above for the short wavelength grating. The photometric calibration was extended above $360 \AA$ by using the line ratio technique. The line ratios chosen were the well understood ${ }^{2} \mathrm{~S}_{1 / 2}-{ }^{2} \mathrm{P}_{3 / 2}$ and the ${ }^{2} \mathrm{~S}_{1 / 2}-{ }^{2} \mathrm{P}_{1 / 2} s-\mathrm{p}$ transitions in the $\mathrm{Li}$ and $\mathrm{Na}$ like iso sequences. These ratios should be 2:1 in intensity. The actual theoretical ratios were calculated with the HULLAC atomic code. The SPRED measured these lines introduced by the laser blow off technique (listed in table) and those of argon. The GRITS spectrometer was not used in the extension to higher wavelengths. The calibration above $360 \AA$ relied only on the relative sensitivity of the SPRED spectrometer. For these measurements the SPRED's reticon integration time was $20 \mathrm{~ms}$, and microchannel plate high voltage was $700 \mathrm{~V}$. This ASSUMES that the calibration in Show is normalized to $750 \mathrm{~V}$. To adjust the calibration to $700 \mathrm{~V}$ divide by 0.4 . This data was acquired during the November to December 1997 and the June to July 1998 run periods. The error in the calibration is $\pm 35 \%$ at $300 \AA$ and increases to about a factor of 2 at $1000 \AA$. The photometric calibration was the best fit to the data which is plotted in figure \#2. The calibration beyond $1000 \AA$ is an extrapolation of that below $1000 \AA$ since no suitable emission lines existed above $1000 \AA$.

The best fit for the wavelengths above $470 \AA$ is:

$$
\Gamma=10^{\left(a_{0}+a_{1}{ }^{*} x\right)}: R=0.99
$$

with coefficients:

\begin{tabular}{ll}
\hline Coefficient & Value \\
\hline $\mathrm{a}_{0}$ & 7.0849 \\
$\mathrm{a}_{1}$ & 0.0045025 \\
\hline
\end{tabular}


The best fit for the wavelengths below $470 \AA$ is:

$$
\Gamma=10^{\left(a_{0}+a_{1} x+a_{2} x^{2}+a_{3} x^{3}+a_{4} x^{4}+a_{5} x^{5}+a_{6} x^{6}\right)}: R=0.99
$$

with coefficients:

\begin{tabular}{ll}
\hline Coefficient & Value \\
\hline $\mathrm{a}_{0}$ & 15.649 \\
$\mathrm{a}_{1}$ & 0.035533 \\
$\mathrm{a}_{2}$ & $-2.2248 \mathrm{e}-5$ \\
$\mathrm{a}_{3}$ & $4.0305 \mathrm{e}-7$ \\
$\mathrm{a}_{4}$ & $-7.9951 \mathrm{e}-10$ \\
$\mathrm{a}_{5}$ & $6.1911 \mathrm{e}-13$ \\
$\mathrm{a}_{6}$ & $-1.6909 \mathrm{e}-16$ \\
\hline
\end{tabular}

\section{III) MCP Voltage Calibration}

The relative sensitivity of the SPRED was measured using FTU tokamak plasma as a light source. The SPRED measure lines with the low wavelength grating. The GRITS was measured the same lines (The Mo: $115.9 \AA, 128.7 \AA$, O: $150 \AA$, Ni: $118 \AA$ and Fe: $131.7 \AA$ ) simultaneously. During several plasmas the voltage was varied on the MCP of the SPRED. The relative sensitivity is shown in figure \#3 and the best fit to the data is:

$$
R=\left(\frac{1}{0.93628}\right) \exp \left(\begin{array}{c}
-877.17+4.4627 * V-0.0085316 * V^{2} \\
+7.247 \times 10^{-6} * V^{3}-2.3038 \times 10^{-9} * V^{4}
\end{array}\right)
$$




\section{IV) Wavelength Calibration}

The fits to the wavelength in Angstroms as a function of pixel are shown in figure $\# 4$ and the fits are given by:

Low wavelength grating $(100-300 \AA)$ :

$$
\text { Wave }=90.008+0.19213 * P+4.0365 \times 10^{-5} * P^{2}-1.6337 \times 10^{-8} * P^{3}
$$

High wavelength grating $(200-1800 \AA)$ :

$$
\text { Wave }=199.82+1.3267 * P+0.004371 * P^{2}-3.0212 \times 10^{-7} * P^{3}
$$




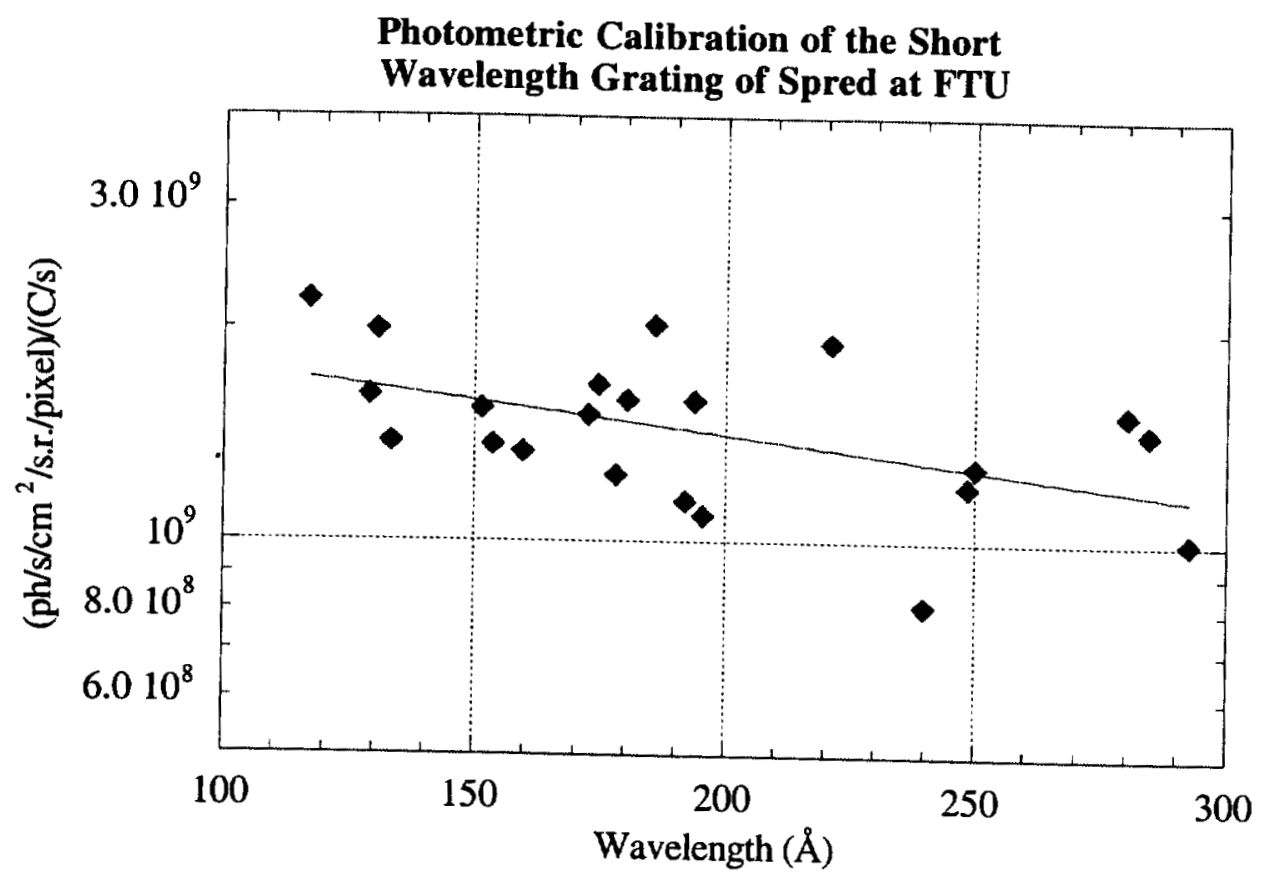

Figure \#1

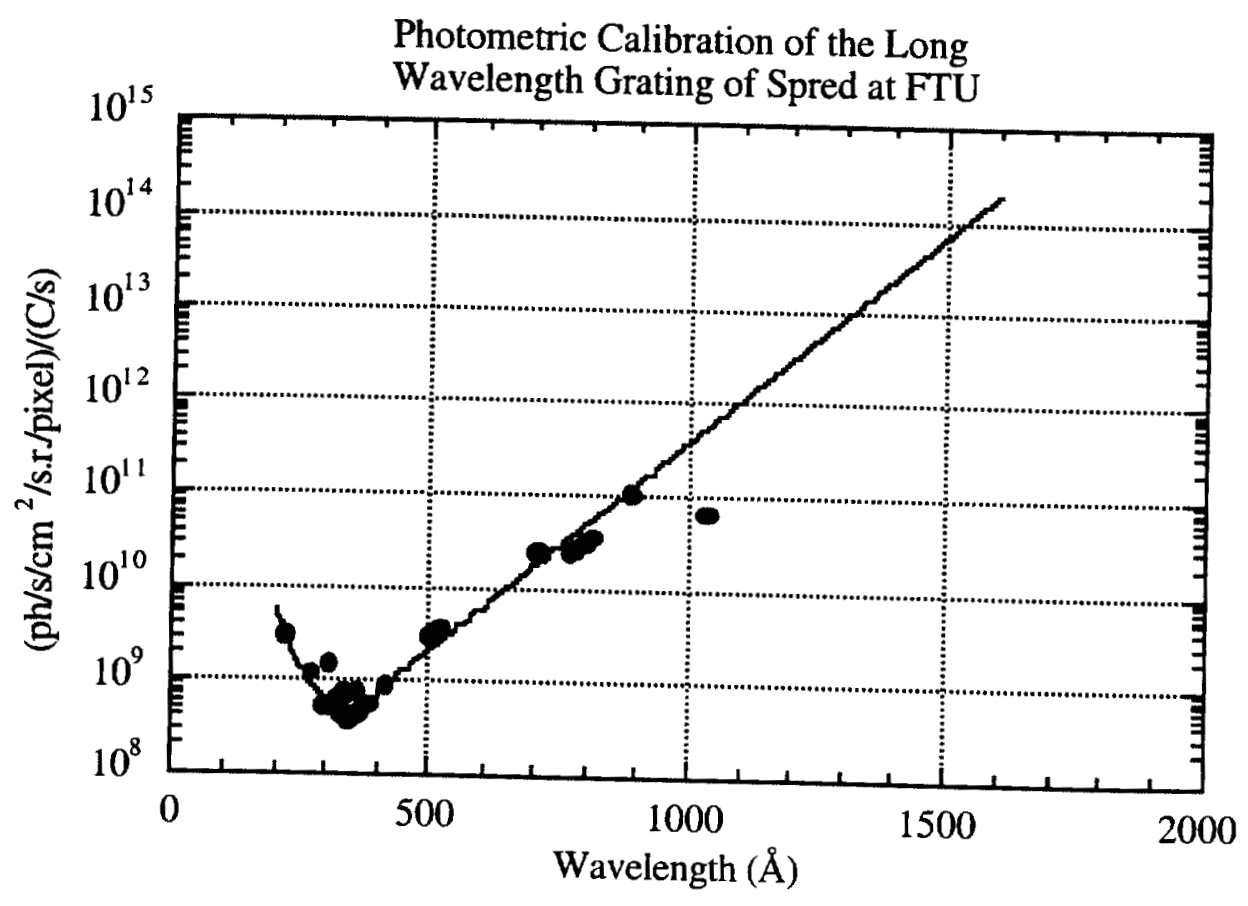

Figure \#2 


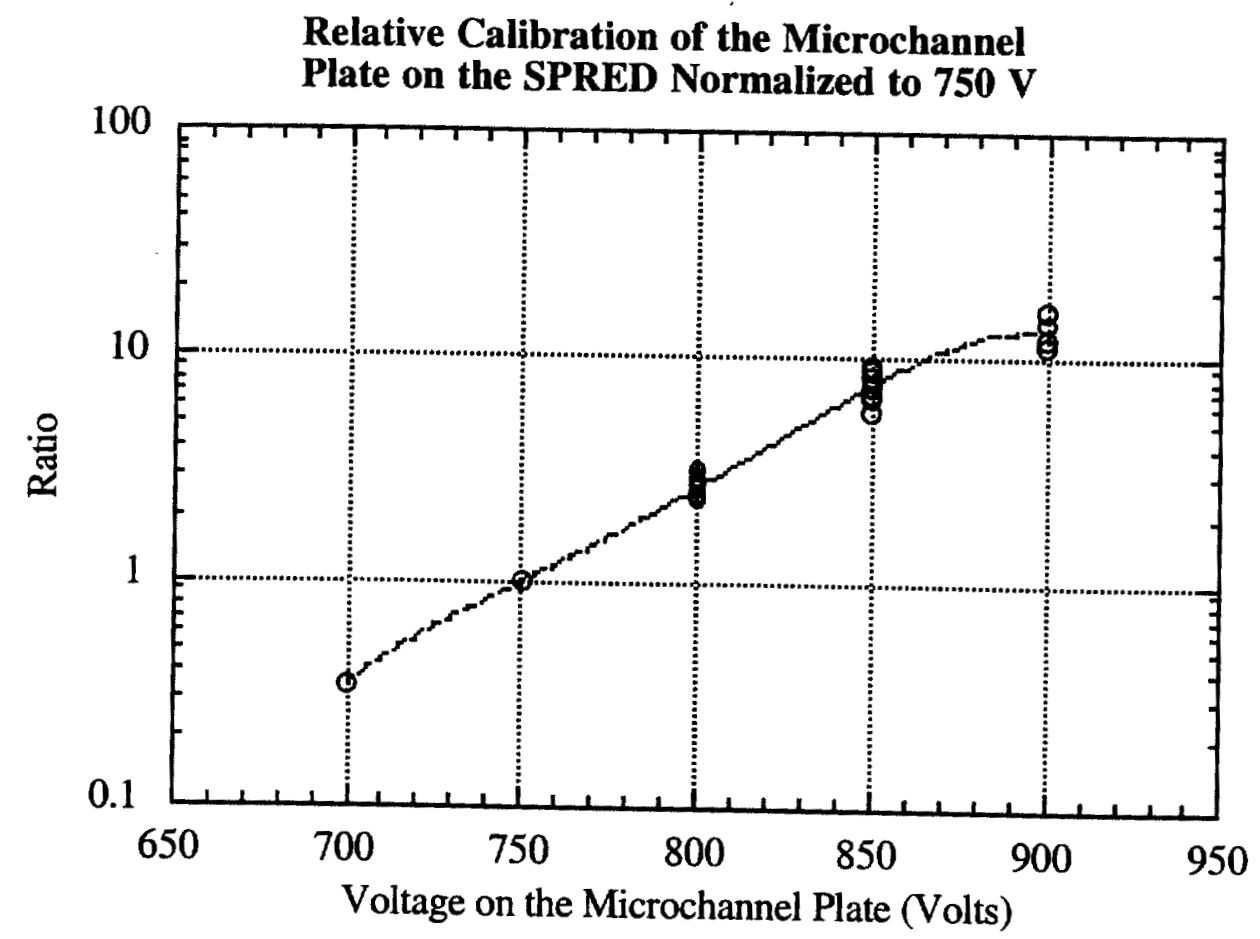

Figure \#3

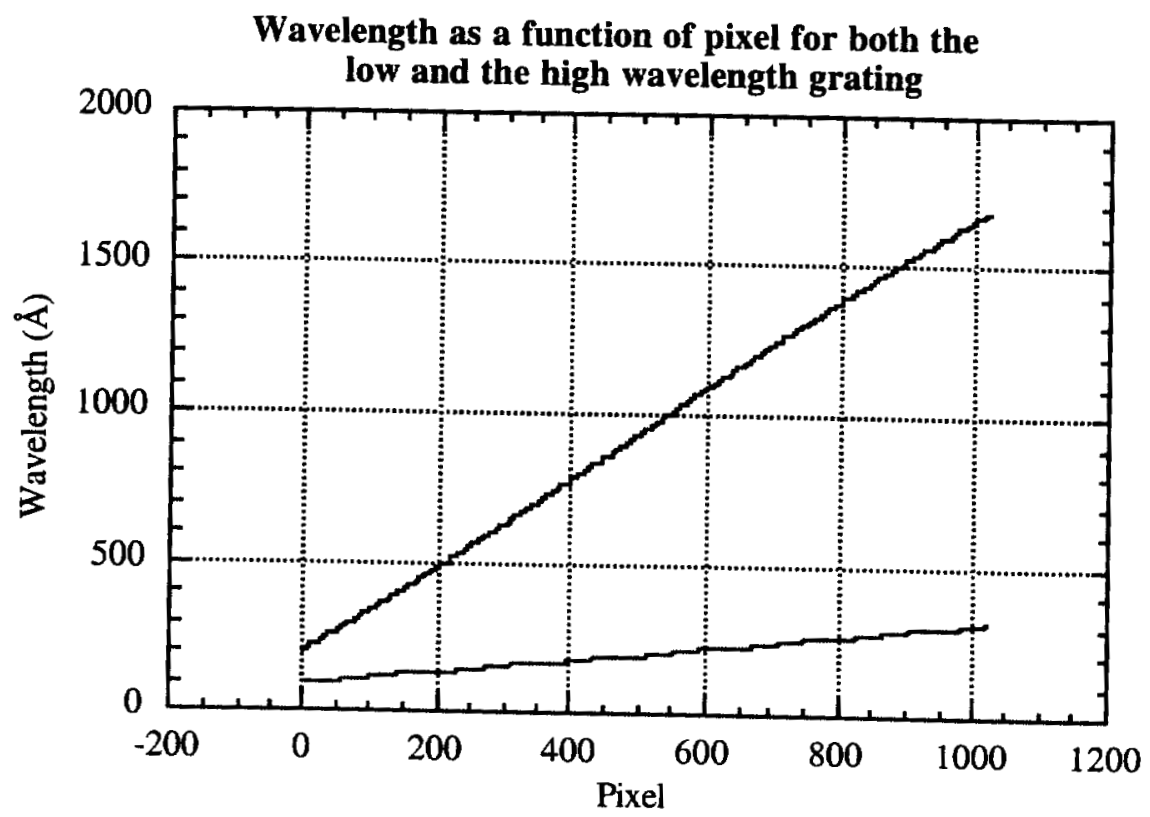

Figure \#4 


\begin{tabular}{lllll}
\hline $\begin{array}{l}\text { Charge } \\
\text { State }\end{array}$ & $\begin{array}{l}\text { Iso } \\
\text { Sequence }\end{array}$ & $\begin{array}{l}\text { Wavelength }(\AA) \\
\text { Transition } \\
(1 / 2-3 / 2)\end{array}$ & $\begin{array}{l}\text { Wavelength }(\AA) \\
\text { Transition } \\
(1 / 2-1 / 2)\end{array}$ & $\begin{array}{l}\text { HULLAC line } \\
\text { ratios }\end{array}$ \\
\hline $\mathrm{Ni}^{25+}$ & $\mathrm{Li}$ & 164.42 & 234.20 & 1.84 \\
$\mathrm{Fe}^{23+}$ & $\mathrm{Li}$ & 192.07 & 255.09 & 1.87 \\
$\mathrm{Cr}^{21+}$ & $\mathrm{Li}$ & 223.0 & 279.7 & 1.89 \\
$\mathrm{Ti}^{19+}$ & $\mathrm{Li}$ & 259.296 & 309.104 & - \\
$\mathrm{Cu}$ & $\mathrm{Na}$ & 273.361 & 303.57 & 1.92 \\
$\mathrm{Ni}^{17+}$ & $\mathrm{Na}$ & 291.97 & 320.537 & 1.94 \\
$\mathrm{Ca}^{17+}$ & $\mathrm{Li}$ & 302.2 & 344.8 & 1.97 \\
$\mathrm{~K}^{16+}$ & $\mathrm{Li}$ & 326.72 & 365.66 & 1.94 \\
$\mathrm{Fe}^{15+}$ & $\mathrm{Na}$ & 335.407 & 360.797 & 1.96 \\
$\mathrm{Ar}^{15+}$ & $\mathrm{Li}$ & 353.92 & 389.14 & 1.90 \\
$\mathrm{Cl}^{14+}$ & $\mathrm{Li}$ & 383.96 & 415.5 & 1.96 \\
$\mathrm{Cr}^{13+}$ & $\mathrm{Na}$ & 390.81 & 482.2 & 1.96 \\
$\mathrm{Ti}^{11+}$ & $\mathrm{Na}$ & 460.741 & 478.881 & - \\
$\mathrm{Si}^{11+}$ & $\mathrm{Li}$ & 499.40 & 520.67 & 1.98 \\
$\mathrm{Ca}^{9+}$ & $\mathrm{Na}$ & 557.8 & 574.0 & 1.94 \\
$\mathrm{~K}^{8+}$ & $\mathrm{Na}$ & 621.452 & 636.325 & 1.96 \\
$\mathrm{Ar}^{7+}$ & $\mathrm{Na}$ & 700.245 & 713.812 & 1.94 \\
$\mathrm{Ne}^{7+}$ & $\mathrm{Li}$ & 770.409 & 780.324 & 1.99 \\
$\mathrm{Cl}^{6+}$ & $\mathrm{Na}$ & 800.64 & 812.64 & 1.98 \\
$\mathrm{~F}^{6+}$ & $\mathrm{Li}$ & 883.1 & 890.8 & 1.99 \\
$\mathrm{O}^{5+}$ & $\mathrm{Li}$ & 1031.924 & 1037.614 & 1.99 \\
$\mathrm{Si}^{3+}$ & $\mathrm{Na}$ & 1393.755 & 1402.770 & - \\
\hline
\end{tabular}

Wavelengths of the s-p transitions in the $\mathrm{Li}$ and $\mathrm{Na}$ like iso sequences used in the calibration of the long wavelength SPRED grating. 